\title{
Amadeus
}

International Multidisciplinary Journal ISSSN 2525-8281

DOI: $10.14295 /$ aimj.v5i10.157

\section{Um ano de Covid-19: Como a pandemia tem atingido a população brasileira?}

Há mais de um ano o mundo está sofrendo os efeitos da pandemia. Atualmente, alguns países estão conseguindo controlar a situação, como é o caso da China, Japão e Portugal, no entanto, a grande maioria continua lutando desesperadamente contra a Covid-19, sofrendo, inclusive, os impactos de uma nova cepa que tem se espalhado rapidamente pela população, como é o caso do Brasil.

Atualmente, a Covid-19 tem causado a morte de mais de duas mil pessoas em 24 horas, o que demonstra a velocidade com a qual a doença se espalha, bem como revela a gravidade da situação. Em 29 de abril de 2020, o G1 trouxe o panorama atroz de que "O Brasil registrou 1.969 mortes por Covid nas últimas 24 horas $e$ totalizou nesta segunda (29) 314.268 óbitos. Com isso, a média móvel de mortes no país nos últimos 7 dias chegou a 2.655, um novo recorde desde o início da pandemia pelo $4^{o}$ dia consecutivo. Em comparação à média de 14 dias atrás, a variação foi de $+34 \%$, indicando tendência de alta nos óbitos pela doença" (G1, 2021).

E tudo indica que esse quantitativo ainda vai crescer, o que causa uma preocupação generalizada:

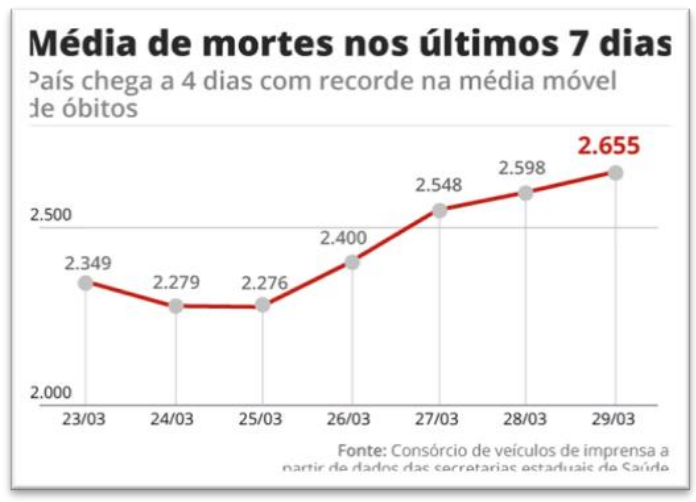

Fonte: Portal G1 
Diariamente, os noticiários apresentam informações sobre o aumento do número de infectados pelo vírus, o que tem ocasionado a decretação de novo lockdown em muitos estados do Brasil. É assustador ver o aumento do número de contágio, pois a incerteza sobre o fim da pandemia assusta, desanima, causa ansiedade.

Em todo esse tempo, a liberdade de ir e vir, assim como o convívio social, foram limitados em razão da necessidade do isolamento social para fins de contenção da disseminação da doença de forma descontrolada. No entanto, apesar desacelerar a propagação do vírus, essas restrições atingiram negativamente a saúde mental de muitas pessoas, o que é preocupante.

Dados da Organização Mundial da Saúde (OMS), aponta que o Brasil é o país com maio índice de depressão da América Latina. Além disso, é o país com o maior quantitativo de pessoas que sofrem de ansiedade. Essas informações são preocupantes, uma vez que a doutrinadores da psiquiatria afirmam que o sentimento de solidão é um dos principais gatilhos dos transtornos de humor.

Sem dúvidas, a pandemia tem configurado um momento de sofrimento psicológico na população, o que desencadeia transtornos mentais variados. Com isso, temos visto muitos psicólogos oferecendo apoio profissional de forma on-line, como forma de tentar restabelecer a saúde mental das pessoas durante a pandemia.

Como ainda é preciso manter o isolamento social, ficando o máximo possível em suas casas, os especialistas têm sugerido que, além dos cuidados profissionais, as pessoas coloquem pequenas práticas em dia visando a manutenção da saúde mental, sendo elas:

I.Descansar, pois a regularidade/irregularidade de sono interfere diretamente no equilíbrio emocional;

II.Manter uma boa alimentação, tendo em vista que uma dieta balanceada ajuda no funcionamento dos processos químicos cerebrais;

III.Evitar uso de drogas para tentar aliviar o estresse, uma vez que a utilização de álcool e tabaco são viciantes e causam muitos malefícios físicos e mentais;

IV.Manter contato com amigos e familiares utilizando meios de comunicação à distância, visando aumentar a percepção de que existe uma rede de apoio com a 
qual se pode contar, bem como para aliviar as sensações negativas da pandemia; e

V.Realizar atividades não obrigatórios, ou seja, ler um livro, atividade física, assistir filmes, cozinhar etc.

Outrossim, não podemos esquecer que o isolamento, assim como a decretação de lockdown também tem prejudicado a economia (produtividade e consumo), atingindo todos os tipos de comércio, mormente os pequenos empresários. A diminuição de faturamento para alguns foi tão grande, que alguns tiveram que demitir funcionários e até fechar as portas.

Isso foi outro motivo que mexeu demais com a população, pois sua grande maioria é composta por pessoas de baixa renda, que não podem suportar essa limitação ou fechamento do comércio por muito tempo. Ainda, boa parte dos trabalhadores são informais, que precisam do fluxo de pessoas nas ruas para poder obter algum tipo de renda.

É um momento delicado, pois a pandemia exige a modificação de hábitos, o que tem incorporado da sociedade um "novo normal". Com isso, devemos seguir as regras preventivas recomendadas pelos órgãos oficiais, as quais determinam:

I.O uso de máscara em espaços públicos;

II.Higienização frequente das mãos, com água e sabão ou álcool em gel;

III.Distanciamento das pessoas, principalmente se elas estiverem espirrando ou tossindo;

IV.Evitar tocar nos olhos, nariz e boca;

V.Cobrir com o braço a boca ou nariz caso vá tossir ou espirrar;

VI.Ficar em casa, apensar saindo se extremamente necessário; e

VII.Procurar atendimento em caso de febre, tosse e dificuldade para respirar.

As orientações precisam, de fato, ser postas em prática, sem questionamentos e sem desculpas, pois é incontroverso a relevância que possuem, mormente quando se percebe que há mais de um ano o país tem lutado para controlar a Covid-19 e, em alguns lugares, ela tem voltado a se alastrar. 
$\mathrm{O}$ vírus continua matando amigos e familiares, o que impõe à sociedade a necessidade de resguardo para que haja o controle efetivo da doença, pois isso impede a disseminação descontrolada da Covid-19.

Então, como se pode notar, o final dessa jornada ainda é incerto, assim como a forma como essa enfermidade vai se perpetuar em cada sociedade. Assim, até que seja possível vacinar toda a população, é muito importante que todos cumpram à risca com as orientações oficiais, como forma de colaborar com o efetivo controle da doença.

\section{Athena de Albuquerque Farias ${ }^{1}$ \\ Senior Editor}

\section{Referências}

FIOCRUZ. Saúde mental e atenção psicossocial na pandemia COVID-19. Fiocruz, 2020. Disponível em: $\quad<$ https://www.fiocruzbrasilia.fiocruz.br/wpcontent/uploads/2020/04/Sa\%C3\%BAde-Mental-e-Aten\%C3\%A7\%C3\%A3o-Psicossocial-naPandemia-Covid-19-recomenda\%C3\%A7\%C3\%B5es-gerais.pdf >. Acesso em 30/03/2021.

G1. Brasil registra quase 2 mil mortes por Covid em $\mathbf{2 4}$ horas; média móvel passa de 2.600 por dia. 2021. https://g1.globo.com/bemestar/coronavirus/noticia/2021/03/29/brasil-registra-quase-2-milmortes-por-covid-em-24-horas-media-movel-passa-de-2600-por-dia.ghtmlAcesso em: 30/03/2021.

HUMANISTA. Brasil completa um ano de Covid-19 em meio ao colapso anunciado da saúde. Site UFRGS, 2021. Disponível em: <https://www.ufrgs.br/humanista/2021/03/03/editorial-brasil-completa-um-ano-de-covid-19em-meio-ao-colapso-anunciado-da-saude/>. Acesso em: 30/03/2021.

PFIZER. Saúde mental na pandemia do coronavírus: como manter o bem-estar em tempos de distanciamento social. Pfizer, 2020. Disponível em: < https://www.pfizer.com.br/noticias/ultimas-noticias/saude-mental-na-pandemia-docoronavirus-como-manter-o-bem-estar-em-tempos-de-distanciamento-social>. Acesso em: $30 / 03 / 2021$.

PFIZER. Guia de saúde mental pós-pandemia' traz orientações e dicas para problemas psíquicos e emocionais. Pfizer, 2020. Disponível em: $<$ https://www.pfizer.com.br/noticias/releases/guia-de-saude-mental-pos-pandemia-trazorientacoes-e-dicas-para-problemas-psiquicos-e-emocionais>. Acesso em: 30/03/2021.

${ }^{1}$ Lawyer. LLM in Sustainable Development at Università degli Studi di Milano - Italy. 